American Journal of Biochemistry and Biotechnology 7 (2): 70-73, 2011

ISSN 1553-3468

(C) 2011 R.D. Long et al., This open access article is distributed under a Creative Commons Attribution

(CC-BY) 3.0 license

\title{
Mixed-Polarity Azeotropic Solvents for Efficient Extraction of Lipids from Nannochloropsis Microalgae
}

\author{
Robert D. Long and Elseddik Abdelkader \\ Department of Physical Sciences, Eastern New Mexico University, \\ Station 33, Portales, NM, 88130, USA
}

\begin{abstract}
Problem statement: The extraction of lipids from microalgae for biofuel production is a significant problem due to the intractability of their cell wall. The aim of this study of lipid extraction from Nannochloropsis microalgae was to examine the relative efficiencies of some commonly used solvent systems and test the use of co-boiling solvents in Soxhlet extraction as an improved method. Approach: We conducted a series of trials of lipid extraction from dried Nannochloropsis microalgae powder by conventional methods and compared the results to low boiling point mixed-polarity azeotropic solvent mixtures in Soxhlet extraction (a technique which has not previously been reported). Results: We found that in conventional room temperature solvent extractions, the chloroform/methanol protocols gave higher yields of lipids from Nannochloropsis than a hexane/isopropanol mixture. In testing Soxhlet extractions, we found that superior results could be obtained with hydrocarbon/alcohol azeotropic mixtures compared to hydrocarbon only solvents (i.e., hexane, cyclohexane), especially with a cyclohexane/butanol (9:1 ratio) mixture. Conclusion: The latter results indicate the potential for performing efficient microalgae lipid extractions with nonhalogenated solvent systems in the future (a greener alternative).
\end{abstract}

Key words: Lipid extraction, algal oil, soxhlet extractions, solvent extractions, solvent systems, extraction protocols, azeotropic solvent, soxhlet extraction, nannochloropsis microalgae, algal biomass

\section{INTRODUCTION}

Biodiesel is an important renewable transportation fuel that can be made from vegetable oils, animal fats, used cooking oil, or algal oil (Demirbas, 2007; Pienkos and Darzins, 2009). Microalgae are efficient photosynthetic factories that have the ability to convert atmospheric carbon (existing as $\mathrm{CO}_{2}$ ) to lipids, especially to Triacylglycerols (TAG's) (Hu et al., 2008). The extraction of these lipids from algal biomass is a necessary first step in their conversion to biodiesel or other biofuels (Sharif Hossain et al., 2008; Schenk et al., 2008; Chisti, 2007).

Extraction of oils from microalgae is a much more difficult problem than extraction of oils from oilseed. Microalgae are single-cell organisms with extremely tough cell walls that can be difficult to disrupt (Sheehan et al., 1998). Thus, techniques other than those used for oilseeds involving ultrasonication, microwaves, electrochemical cell wall disruption, electromechanical cell wall rupture and supercritical fluid extraction are all currently being studied relative to microalgae extraction, in addition to the more conventional solvent extraction methods (Lee et al., 2010; Samorì et al., 2010). Apart from these newer methods, the most common techniques for lipid extraction from microalgae in current use involve chloroform/methanol mixtures or hexane in solvent or Soxhlet extraction. We performed a comparison of different solvent systems using these traditional extraction techniques in order to judge their relative effectiveness.

We also wanted to evaluate whether other nonchlorinated solvent systems could be effective, thus eliminating environmental concerns and down-stream processing problems associated with chlorinated solvents. For this purpose, we examined the use of mixed-polarity (hydrocarbon/alcohol mixture) solvent systems in ratios equivalent to the azeotropic mixture expected to be formed from them in Soxhlet extractions as an alternative technique for lipid extraction.

\section{MATERIALS AND METHODS}

Preparation: Two batches of frozen Nannochloropsis microalgae paste were donated by Center of Excellence

Corresponding Author: Robert D. Long, Department of Physical Sciences, Eastern New Mexico University, Station 33, Portales, NM, 88130, USA 
for Hazardous Materials Management (CEHMM) of Carlsbad, NM for use in this study. Samples from the two batches of algal paste were dried overnight in an oven (nominally set to $80-110^{\circ} \mathrm{C}$ ) for this project. The dried samples were then ground to fine powder (using a Spex Shatterbox with a Spex alumina ceramic grinding container) as preparation for use in extractions. By comparing the wet to dry weights obtained we determined that the algal pastes were 28.9 $(0.2 \%$ std dev) and $28.2(0.4 \%$ std dev $)$ dry mass respectively [71.1 and $71.8 \%$ water/volatiles lost by weight]. Conventional solvent extraction and Soxhlet methods were then applied to the dried microalgae powder to determine which methods gave the highest yield of extracted lipids.

Conventional solvent extraction (room temperature): Protocols used for solvent extraction were based on those reported by Bligh and Dyer (1959), Folch et al. (1957) and a mixture of hexane/isopropanol (Hara and Radin, 1978). For Bligh/Dyer and Folch methods, solvent used was a mixture of chloroform and methanol with a (1:2) ratio for Bligh/Dyer and (2:1) ratio for Folch protocols respectively. Dried algae samples of approximately $5 \mathrm{~g}$ mass were mixed with $100 \mathrm{~mL}$ of solvent and soaked overnight. Solids were removed by filtration and the solvent extract was mixed with $\sim 50 \mathrm{~mL} 0.9 \% \mathrm{NaCl}$ in a separatory funnel and allowed to stand overnight. After separation of the organic phase from brine, the solvent was removed by rotary evaporator. Four replicates of each solvent system were evaluated and the results averaged. Lipid percentage was determined by comparing the extracted algal oil mass to initial dried sample mass.

Soxhlet extraction: For the Soxhlet method (Schafer, 1998), we wanted to evaluate hydrocarbon and binary solvent systems with mixed polarity (hydrocarbon + alcohol). The purpose of using mixed polarity solvents was to emulate the mixed polarity of the commonly used room temperature extraction protocols. For the binary systems we chose some solvent combinations in ratios that would distill as an azeotropic mixture (so that the condensed solvent performing the extraction would have a known composition). We selected five different solvent systems for initial evaluation; hexane, hexane/cyclohexane (1:1), cyclohexane/2-propanol (2:1), hexane/2-propanol (3:1) and cyclohexane/1butanol $(9: 1)$. The ratios for cyclohexane or hexane mixtures with alcohol were selected to be equivalent to the azeotropic mixture ratio, based on mole fractions found in the Azeotrope databank (Ponton, 2001). The azeotropic boiling points for the mixtures selected are all at or below the boiling point of pure hexane (so that no additional energy would be required to perform the extractions).

Dried microalgal powder $(\sim 6 \mathrm{~g})$ was placed in a porous cellulose thimble of internal diameter $25 \mathrm{~mm}$ and height of $80 \mathrm{~mm}$. The thimble was placed in a Soxhlet extraction tube equipped with water-cooled condenser and was suspended above a $500 \mathrm{~mL}$ flask containing $\sim 250 \mathrm{~mL}$ solvent. The extractions were allowed to proceed for about $18 \mathrm{~h}$ with subsequent removal of solvent by rotary evaporator. At least 4 replications of each extraction were performed with the results averaged. The mass of recovered extract was compared to the initial dried algal biomass to determine percent recovery from the extraction process.

IR/NMR: Representative samples of each of the extracts were examined by IR and NMR spectroscopy. Samples for IR were prepared by dissolving in chloroform/methanol mixture, spotted on a $\mathrm{NaCl}$ salt plate and analyzed following solvent evaporation. A ThermoScientific Magna S10 was used for FT/IR analysis. For proton NMR, a representative sample was dissolved in deuteriated chloroform $\left(\mathrm{CDCl}_{3}\right)$ containing TMS reference. The NMR samples were analyzed by 60 MHz FT-NMR (Varian EM-360 with Anasazi FT-NMR upgrade).

\section{RESULTS}

Table 1 contains the results of room temperature extractions using the Bligh/Dyer, Folch and hexane/isopropanol methods. The Folch method appears to give slightly better results than the Bligh/Dyer method (27.1 vs $24.8 \%$ ), but when standard error is considered (2.7 and $4.3 \%$ respectively) it is not clear that this difference is significant. Use of hexane/isopropanol in place of chloroform/methanol gave much lower yields (17.5\% average with $3.4 \%$ standard error).

Table 1:Experimental results of different solvents used in simple solvent extraction method

\begin{tabular}{lllll}
\hline Solvent & \# Samples & Range (\%) & Mean (\%) & SD (\%) \\
\hline Bligh/dyer & 8 & $20.8-32.0$ & 24.8 & 4.3 \\
Folch & 8 & $23.9-31.5$ & 27.2 & 2.7 \\
Hexane/2-propanol (3:2) & 8 & $11.9-21.8$ & 17.5 & 3.4
\end{tabular}


Am. J. Biochem. \& Biotech., 7 (2): 70-73, 2011

Table 2: Experimental results with different solvents used in Soxhlet extraction

\begin{tabular}{lllllll}
\hline Solvent & Ratio & Predicted b.p. ${ }^{\mathrm{a}}$ & Samples & Range (\%) & Mean (\%) \\
\hline Hexane & n/a & $86^{\circ}$ & 8 & $15.7-17.0$ & 16.1 & SD (\%) \\
Hexane/cyclohexane & $1: 1$ & $86 / 84^{\circ}$ & 4 & $18.8-20.2$ & 19.6 \\
Cyclohexane/2-propanol & $2: 1$ & $69^{\circ}$ & 4 & $26.3-32.8$ & 29.7 & 0.6 \\
Hexane/2-propanol & $3: 1$ & $61^{\circ}$ & 4 & $25.5-31.9$ & 27.7 \\
Cyclohexane/1-Butanol & $9: 1$ & $80^{\circ}$ & 4 & $31.2-35.4$ & 33.7 & 2.9 \\
\hline
\end{tabular}

${ }^{\mathrm{a}}$ Boiling points for azeotropic mixtures from Azeotrope database (Ponton, 2001)

Table 2 shows the results from Soxhlet extraction with different solvent systems. The mixed polarity solvent systems with alcohols gave better overall yields than the hydrocarbon only extractions. The azeotropic mixture of cyclohexane/1-butanol gave the highest yields (average $33.7 \%$ with standard error of $1.9 \%$ ) of all extraction protocols tested.

IR and NMR spectra of representative samples were found to be consistent with a mixture of lipids (saturated and unsaturated) consistent with the presence of tri-, di- and/or mono-acylglycerols with minor components of free fatty acids and possibly more complex lipids. There was no significant difference noted in the spectra of samples from alternative extraction protocols.

\section{DISCUSSION}

In this study we found that the chloroform/methanol protocols gave the highest extract yields for room temperature solvent extraction of the dried microalgae samples we investigated $(25-27 \%$ for these vs. $17 \%$ for hexane/isopropanol). Clearly, a higher polarity in room temperature extractions of microalgae is advantageous for more complete extractions.

In our investigation of Soxhlet protocols we have observed that hydrocarbon only extractions are not as effective as extraction with azeotropic mixtures of mixed polarity. The yield from Soxhlet extraction with mixed polarity azeotropes (28-34\%) gave yields that are comparable to or surpass those of chloroform/methanol extractions at room temperature. In particular, the Soxhlet extraction with cyclohexane/1-butanol (9:1) was especially attractive ( $34 \%$ yield).

Our preliminary characterization of the lipid extracts by IR/NMR did not reveal any significant differences in the extracts from the different protocols. However, a more detailed study of the lipid profiles present in the extracts is warranted for future study.

\section{CONCLUSION}

Our results indicate that solvents other than chloroform or hexane can potentially be used for efficient extraction of lipids from microalgae, which may be necessary before these processes can be scaled up (for environmental reasons). In particular, an azeotropic mixture of cyclohexane with 1-butanol (which can be produced as a biofuel also) showed good promise as an effective and greener alternative solvent system.

\section{ACKNOWLEDGEMENT}

The reasearchers are grateful to Eastern New Mexico University for financial support of this stydy through an internal grant and to Center of Excellence for Hazardous Materials Management (CEHMM) in Carlsbad, NM for generously supplying us with the microalgae paste for our research.

\section{REFERENCES}

Bligh, E.G. and W.J. Dyer, 1959. A rapid method of total lipid extraction and purification. Can. J. Biochem. Physio., 37: 911-917. PMID: 13671378

Chisti, Y., 2007. Biodiesel from microalgae. Biotechnol. Adv., 25: 294-306. DOI: 10.1016/j.biotechadv.2007.02.001

Demirbas, A., 2007. Importance of biodiesel as transportation fuel. Energy Policy, 35: 4661-4670. DOI: 10.1016/j.enpol.2007.04.003

Folch, J., M. Lees and G.H.S. Stanley, 1957. A simple method for the isolation and purification of total lipids from animal tissues. J. Biol. Chem., 226: 497-509. PMID: 13428781

Hara, A. and N.S. Radin, 1978. Lipid extraction of tissues with a low-toxicity solvent. Anal. Biochem. 90: 420-426. DOI: 10.1016/0003-2697(78)90046-5

Hu, Q., M. Sommerfeld, E. Jarvis, M. Ghirardi and M. Posewitz et al., 2008. Microalgal triacylglycerols as feedstocks for biofuel production: Perspectives and advances. Plant J., 54: 621-639. DOI: 10.1111/j.1365-313X.2008.03492.X

Lee, J.Y., C. Yoo, S.Y. Jun, C.Y. Ahn and H.M. Oh, 2010. Comparison of several methods for effective lipid extraction from microalgae. Biores. Technol., 101: 75-77. DOI: 10.1016/j.biortech.2009.03.058

Pienkos, P.T. and A. Darzins, 2009. The promise and challenges of microalgal-derived biofuels. Biofuels, Bioproducts Biorefin., 3: 431-440. DOI: 10.1002/bbb.159 
Ponton, J., 2001. Azeotrope databank. The Edinburgh Collection of Open Software for Simulation and Education, Edinburgh University.

Samorì, C., C. Torri, G. Samorì, D. Fabbri and P. Galletti et al., 2010. Extraction of hydrocarbons from microalga Botryococcus braunii with switchable solvents. Biores. Technol., 101: 3274-3279. DOI: 10.1016/j.biortech.2009.12.068

Schafer, K., 1998. Accelerated solvent extraction of lipids for determining the fatty acid composition of biological material. Anal. Chim. Acta, 358: 69-77. DOI: 10.1016/S0003-2670(97)00587-4
Schenk, P.M., S.R. Thomas-Hall, E. Stephens, U.C. Mussgnug and J.H. Posten et al., 2008. Second Generation Biofuels: High-efficiency microalgae for biodiesel production. Bioenergy Res., 1: 20-43. DOI: $10.1007 / \mathrm{s} 12155-008-9008-8$

Sharif Hossain, A.B.M., A. Salleh, A.N. Boyce, P. Chowdhury and M. Naqiuddin, 2008. Biodiesel fuel production from algae as renewable energy. Am. J. Biochem. Biotechnol., 4: 250-254. DOI: 10.3844/ajbbsp.2008.250.254

Sheehan, J., T. Dunahay, J. Benemann and P. Roessler, 1998. Look Back at the US Department of Energy's Aquatic Species Program: Biodiesel from Algae; Close-Out Report. TP-580-24190, pp: 1-325. 